\section{Selective oxidation of cyclohexanol to cyclohexanone in the ionic liquid 1-octyl-3-methylimidazolium chloride}

\author{
Long Chen, ${ }^{a}$ Teng Zhou, ${ }^{a}$ Lifang Chen, ${ }^{a}$ Yinmei Ye, ${ }^{a}$ Zhiwen Qi, ${ }^{* a}$ Hannsjörg Freund ${ }^{b}$ and \\ Kai Sundmacher ${ }^{b c}$
}

Received 22nd May 2011, Accepted 4th July 2011

DOI: $10.1039 / \mathrm{c} 1 \mathrm{cc12989a}$

Ionic liquid (IL) 1-octyl-3-methylimidazolium chloride was found to effectively intensify cyclohexanol oxidation and resulted in $100 \%$ conversion of cyclohexanol with $100 \%$ selectivity to cyclohexanone using hydrogen peroxide as an oxidant and $\mathrm{WO}_{3}$ as a catalyst. The effect of the IL as a solvent is discussed with the support of COSMO-RS theory.

Cyclohexanone is a key chemical intermediate in the production of precursors to Nylon 6,6 and Nylon 6. It is also an excellent solvent widely used in coating processes. The industrial processes for producing cyclohexanone are based on (1) oxidation of cyclohexane, ${ }^{1}$ (2) hydrogenation of phenol, ${ }^{2}$ or (3) oxidation of cyclohexanol. ${ }^{3}$ The first process requires high temperature around $150{ }^{\circ} \mathrm{C}$ at pressure between 1 and $2 \mathrm{MPa}$. It results in about $4 \%$ conversion of cyclohexane only and generates a significant amount of by-products, in particular cyclohexanol and organic acids. ${ }^{4}$ On the phenol hydrogenation route, cyclohexanone is obtained by a "one-step" or a "two-step" process. However, this option suffers from the high phenol price and from the fact that two hydrogen molecules are needed for hydrogenation which leads to an energy intensive process. ${ }^{5}$ Regarding the third route, cyclohexanol oxidation is performed with stoichiometric amounts of inorganic oxidants, notably chromium(VI) reagents, using environmentally harmful solvents, namely chlorinated hydrocarbons. Moreover, this oxidation route needs high temperature of $200-300{ }^{\circ} \mathrm{C}$ and is energy intensive ${ }^{6}$ Due to the just mentioned disadvantages, it is desirable to develop an alternative process for producing cyclohexanone by selective oxidation of cyclohexanol under mild conditions using oxidants containing molecular oxygen such as hydrogen peroxide. The latter oxidant is also attractive because the sole by-product released during oxidation with hydrogen peroxide is water.

In last two decades, clean technologies based on environmentally friendly solvents ("green solvents") have become

\footnotetext{
a State Key Laboratory of Chemical Engineering, School of Chemical Engineering, East China University of Science and Technology, 130 Meilong Road, Shanghai 200237, China.

E-mail: zwqi@ecust.edu.cn; Fax: + 86 21-64253528

${ }^{b}$ Max Planck Institute for Dynamics of Complex Technical Systems, Sandtorstrasse 1, D-39106 Magdeburg, Germany

${ }^{c}$ Process Systems Engineering, Otto-von-Guericke-University

Magdeburg, Universitätsplatz 2, D-39106 Magdeburg, Germany
}

increasingly attractive for both industry and academia. ${ }^{7}$ Particularly, due to their special physical-chemical properties, ionic liquids (ILs) have enormous potential for the improvement of chemical processes, namely with regard to the enhancement of reaction rates or with regard to the isolation of desired products. ${ }^{8}$ In oxidation processes, most ionic liquids are inert and stable so that they act as pure solvents. ${ }^{9}$ Concerning the oxidation of cyclohexanol in ionic liquids, to the best of our knowledge, there is no report in the open literature available so far. Thus, in the here reported study, we have investigated the application of ionic liquids (ILs) as solvents in the liquid phase oxidation of cyclohexanol to cyclohexanone under mild reaction conditions, $\dagger$ using aqueous $30 \% \mathrm{H}_{2} \mathrm{O}_{2}$ as an oxidant and tungsten oxide $\left(\mathrm{WO}_{3}\right)$ as a catalyst. Furthermore, we compared the performance of ILs with traditional solvents.

It was reported by Usui and Sato ${ }^{10}$ that at $90{ }^{\circ} \mathrm{C}$ cyclohexanol was converted to adipic acid at $90 \%$ conversion after $20 \mathrm{~h}$, using $\mathrm{WO}_{3}$ as a catalyst, while a little amount of adipic acid was found under mild conditions. In the present work, firstly we have evaluated the possibility of producing cyclohexanone from cyclohexanol using the same catalyst at $70{ }^{\circ} \mathrm{C}$. As can be seen in Table 1 (entry 1), by using tungsten oxide as a catalyst without any solvent, cyclohexanol can be oxidized to cyclohexanone with $42 \%$ conversion and $100 \%$ selectivity. A blank oxidation experiment carried out in the absence of the catalyst showed a very slow rate (Table 1 , entry 2 ) leading to only $1.8 \%$ conversion after two hours, suggesting that $\mathrm{H}_{2} \mathrm{O}_{2}$ is not able to oxidize cyclohexanol without tungsten oxide.

Secondly, methanol, $n$-propanol, acetone, and several methylimidazolium-based ILs were applied as solvents for cyclohexanol oxidation. ${ }^{11}$ As listed in Table 1, the selected ionic liquids were [HOemim]Cl (1-hydroxyethyl-3-methylimidazolium chloride), [Hmim] Cl (1-hexyl-3-methylimidazolium chloride), and [Omim] Cl (1-octyl-3-methylimidazolium chloride).

In the third step, the ionic liquid [Omim] $\mathrm{Cl}$, which showed the best solvent performance in the tungsten oxide-catalyzed cyclohexanol oxidation, was used to study the effect of various reaction parameters (entries 3-7 in Table 1). Increasing the amount of $[\mathrm{Omim}] \mathrm{Cl}$ from $1.4 \mathrm{~mol} \%$ to $3.4 \mathrm{~mol} \%$, the conversion of cyclohexanol increased from $82 \%$ to $100 \%$. The IL concentration has already been observed to influence the productivity. ${ }^{12} \mathrm{~A}$ possible reason for this observation might be the influence of the solvent on the energy level and 
Table 1 The performance of various solvents for cyclohexanol oxidation

\begin{tabular}{lllll}
\hline Entry & Solvent $(\mathrm{mol} \%)$ & $\begin{array}{l}\text { Catalyst } \\
(\mathrm{mol} \%)\end{array}$ & $\begin{array}{l}\text { No. of } \\
\text { phases }\end{array}$ & $\begin{array}{l}\text { Cyclohexanol } \\
\text { conversion }(\mathrm{wt} \%)\end{array}$ \\
\hline 1 & None & $\mathrm{WO}_{3}(0.6)$ & 2 & $42 \%$ \\
2 & None & $\mathrm{None}^{2}$ & 2 & $1.8 \%$ \\
3 & [Omim]Cl (3.4) & $\mathrm{WO}_{3}(0.6)$ & 2 & $100 \%$ \\
4 & [Omim]Cl (1.4) & $\mathrm{WO}_{3}(0.6)$ & 2 & $82 \%$ \\
5 & [Omim]Cl (3.4) & $\mathrm{WO}_{3}(0.6)$ & 2 & $65 \% @ 60{ }^{\circ} \mathrm{C}^{a}$ \\
6 & [Omim]Cl (3.4) & $\mathrm{WO}_{3}(0.3)$ & 2 & $84 \%$ \\
7 & [Omim]Cl (3.4) & $\mathrm{None}^{2}$ & 2 & $1.8 \%$ \\
8 & [Hmim]Cl (3.4) & $\mathrm{WO}_{3}(0.6)$ & 2 & $78 \%$ \\
9 & [Bmim]Cl (3.4) & $\mathrm{WO}_{3}(0.6)$ & 2 & $70 \%$ \\
10 & Methanol (58.7) & $\mathrm{WO}_{3}(0.25)$ & 1 & $46 \%$ \\
11 & $n$-Propanol (58.7) & $\mathrm{WO}_{3}(0.25)$ & 1 & $40 \%$ \\
12 & Acetone (58.7) & $\mathrm{WO}_{3}(0.25)$ & 1 & $36 \%$ \\
13 & [HOemim]Cl (3.4) & $\mathrm{WO}_{3}(0.6)$ & 2 & $57 \%$
\end{tabular}

Reaction conditions: cyclohexanol $1 \mathrm{~g}(10 \mathrm{mmol})$, hydrogen peroxide $2 \mathrm{~g}(60 \mathrm{mmol})$, temp. $70{ }^{\circ} \mathrm{C}$ expect otherwise specified, reaction time $2 \mathrm{~h} .{ }^{a}$ When reaction time was increased to $8 \mathrm{~h}$ and $20 \mathrm{~h}, 74 \%$ and $76 \%$ conversion was obtained, respectively.

the stability of transition states in the course of the catalytic reaction. Moreover, the conversion of cyclohexanol was improved significantly when the reaction temperature was increased from $60{ }^{\circ} \mathrm{C}$ to $70{ }^{\circ} \mathrm{C}$ (see entries 3 and 5 in Table 1). For the purpose of producing cyclohexanone, $70{ }^{\circ} \mathrm{C}$ was found to be the optimal reaction temperature. Moreover, the effect of the catalyst loading was investigated. The reduction from $0.6 \mathrm{~mol} \%$ $\mathrm{WO}_{3}$ to $0.3 \mathrm{~mol} \%$ resulted in a reduction of conversion from $100 \%$ to $84 \%$ after $2 \mathrm{~h}$ batch reaction time (entries 3 and 6 in Table 1).

We also found that the length of the IL alkyl chain has a significant effect on the reaction kinetics (compare entries 3, 8 and 9 , Table 1 ). In the case of ionic liquids of type $\left[\mathrm{C}_{n} \mathrm{~min}\right] \mathrm{Cl}$, the conversion of cyclohexanol was increased considerably when increasing the carbon chain length. A similar effect of the alkyl chain length was observed by Hardacre et al. during their study on the copolymerisation of styrene and carbon monoxide. ${ }^{12 a}$ This can be attributed to the extended hydrophobicity of ILs with longer alkyl chains because of stronger associations with the hydrophobic substrate. One can infer that hydrophobic ionic liquids are more suitable for the investigated reaction.

The first report on the use of an ionic liquid as a catalyst was reported in Friedel-Crafts alkylation in 1986. Since then, a large number of papers have been published using ionic liquids as both catalysts and/or solvents. ${ }^{9 a, 13}$ For this reason a control experiment was carried out in the absence of the catalyst $\mathrm{WO}_{3}$, yielding only $1.8 \%$ of product (entry 7 in Table 1). This is as low as the value in entry 2 , giving evidence that the catalytic effect of ILs on cyclohexanol oxidation is negligible. Thus, the investigated ILs act as solvents only.

The polarity of the solvent used can play a very important role for some reactions. ${ }^{14}$ Among the three investigated conventional solvents (entries 10-12) in Table 1, methanol led to the highest conversion $(46 \%)$ and acetone to the lowest $(36 \%)$. A plausible explanation could be based on polarity differences (polarities: methanol $>n$-propanol $>$ acetone). As suggested by Quero et al., ${ }^{15}$ the dependence of the conversion of reactions on the nature of the solvent, i.e. their polarity, can result from differences in the stabilization of reaction intermediate states due to solute-solvent interactions. Thus, the observed increase of conversion with increasing solvent polarity could be attributed to the increased strength of coulombic forces arising during solvation. Entries 10-13 in Table 1 clearly show higher conversion for the ionic liquid [HOemim] $\mathrm{Cl}$ than for the above studied conventional solvents, supporting our hypothesis regarding the effect of the solvent polarity, because [HOemim $] \mathrm{Cl}$ has the highest polarity.

In order to better understand and analyse the experimental results, the theory of COSMO-RS was applied for determining the polarities of the solvents investigated. Briefly, COSMO-RS is a method for predicting thermodynamic properties of fluids or fluid mixtures based on unimolecular quantum chemical calculations in combination with statistical thermodynamics. ${ }^{16}$ In the COSMO-RS theory, the molecule of interest is embedded into a virtual conductor. A screening charge density $\sigma_{i}$ on the nearby conductor will be ultimately induced as a result of the quantum chemical self-consistency iterative computation. The distribution of this polarization charge density is then transferred into a composition function $P^{X}(\sigma)$, named $\sigma$-profile, which indicates the amount of the molecular COSMO surface having the charge density $\sigma_{i}$. Fig. 1 shows $\sigma$-profiles and COSMO-cavities of acetone, 2-propanol, methanol, and [HOemim]Cl. The red colour of the molecular surface indicates a positive surface charge which screens negative partial charges within the molecule. Blue colour indicates a negative surface charge and green symbolizes almost neutral charges. According to COSMO-RS, a lesspolar character of compounds always results in a relatively narrow distribution of the charge densities compared with more polar ones. $\sigma$-Profiles of 2-propanol and methanol are very similar. The far left and right peaks arise from a very polar hydrogen atom and an oxygen atom, respectively. Acetone shows a much narrower $\sigma$-profile due to the more decentralized charge density on the molecular surface. In contrast to the conventional solvents, it is worth to mention that the peaks in the $\sigma$-profile of the IL [HOemim] Cl are much more pronounced. This might originate from the large polar area of the chlorine ion combined with the very polar hydroxyl group. In conclusion, the polarities of the solvents can be ranked as follows: acetone $<2$-propanol $<$ methanol $<$ [HOemim $] \mathrm{Cl}$. This ranking is in agreement with the experiment results.

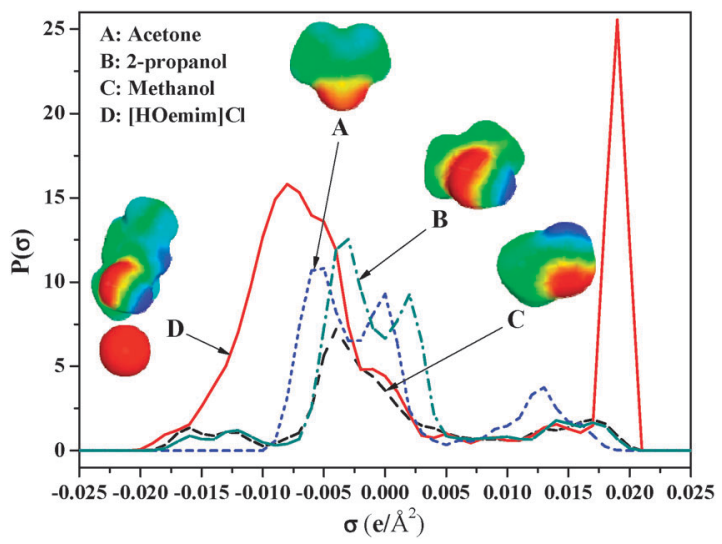

Fig. $1 \sigma$-Profiles and COSMO-cavities of solvent molecules. 
Based on these results of the two studies above, we conclude that the polarity of solvents influences the catalytic reaction to some extent. As known, polar ionic liquids have some hydrophilicity, while cyclohexanol is a hydrophobic substrate. Therefore, hydrophobic ionic liquids tend to be more suitable for this reaction than polar ionic liquids. In fact, this tendency is in good agreement with our experiments (entries 3, 8 and 13 in Table 1). This also explains the effect of the alkyl chain length of hydrophobic ionic liquids on cyclohexanol conversion.

The solubility properties of ILs support a biphasic operating mode during the oxidation reaction. First, the starting material cyclohexanol moves from the organic into the aqueous phase which contains the oxidant $\mathrm{H}_{2} \mathrm{O}_{2}$ and the catalyst $\mathrm{WO}_{3}$. Second, cyclohexanol is oxidized to cyclohexanone. Third, the product is extracted in situ into the organic phase; thereby it is protected against further oxidation. While the investigated classical solvents (methanol, $n$-propanol, acetone) lead to a single phase operating regime, ILs extend the two-phase region of the reaction mixture which results in higher conversion and selectivity. Moreover, the IL-based system allows an efficient separation of cyclohexanone from the oxidant and the catalyst.

In summary, we have studied the solvent effect on the catalytic $\mathrm{H}_{2} \mathrm{O}_{2}$-based liquid phase oxidation of cyclohexanol, comparing three conventional solvents with several ionic liquids. The experimental results show that the investigated ionic liquids allow for significant improvement of conversion and selectivity due to their solubility properties which are related to their polarity and hydrophobicity. Among the studied ILs, [Omim]Cl was found to enable $100 \%$ conversion of cyclohexanol at $100 \%$ selectivity with respect to cyclohexanone at $70{ }^{\circ} \mathrm{C}$. It allows a biphasic reaction regime during which cyclohexanone continuously forms a separate phase, while the oxidant and the catalyst remain in the aqueous phase. After the reaction, the product can be easily isolated by decantation.

In conclusion, high yield and selectivity, ease of product isolation and mild reaction conditions represent the very promising features of the here proposed IL-based liquid phase oxidation process. In future, this may form the basis for the development of a novel green technology for the production of cyclohexanone from cylohexanol.

This research project was financially supported by the Max Planck Partner Group programme of the Max Planck Society in Germany, National Natural Science Foundation of China (NSFC 21076074, 21006029), Shanghai Pujiang Talents Programme (10PJ1402400), Shanghai Scientific and Technological Commission (09DZ1120200), Shanghai Natural Science Foundation (10ZR1407200), the Programme of Introducing Talents of Discipline to Universities (111 Project: B08021) and the Fundamental Research Funds for Central Universities of China.

\section{Notes and references}

$\dagger$ Experimental procedure: the tungsten oxide catalyst used in the reactions was obtained from a commercial source and calcined in air at $500{ }^{\circ} \mathrm{C}$ overnight before use. $30 \% \mathrm{H}_{2} \mathrm{O}_{2}$ and conventional solvents (methanol: 99.9\%, $n$-propanol: $99.7 \%$, acetone: $99.9 \%$ ) were supplied commercially and used without further purification. All ionic liquids were purchased from Lanzhou Institute of Chemical Physics, Chinese
Academy of Science and used as received. In a typical experiment of this work, tungsten oxide was used as a catalyst, which is mixed with solvents including ionic liquids, cyclohexanol $(1 \mathrm{~g}, 10 \mathrm{mmol})$ and hydrogen peroxide $(2 \mathrm{~g}, 60 \mathrm{mmol})$ in a round-bottom flask $\left(25 \mathrm{~cm}^{3}\right)$. The flask was fitted with a reflux condenser and stirred magnetically at $800 \mathrm{rpm}$. The temperature was controlled with a thermocouple. When the specified temperature was reached, stirring starts and the reaction time was recorded. It was found that, with conventional solvents, at the end of the experiment $(2 \mathrm{~h})$, products and nonreacted cyclohexanol formed one single phase. This solution was first dried over anhydrous $\mathrm{MgSO}_{4}$ and then analyzed using GC 7890A from Agilent equipped with a PEG-20M column ( $30 \mathrm{~m}, 0.32 \mathrm{~mm}$ id, $0.25 \mu \mathrm{m}$ film thickness). When ILs were used as solvents, the post-reaction liquid mixture was observed to be split into two separate phases. Each phase was first extracted with ethyl acetate $(3 \times 5 \mathrm{ml})$, then the extracted liquids were mixed and analyzed by the Agilent $7890 \mathrm{~A}$ GC. The product structures were confirmed by comparison with authentic standards of cyclohexanone and by GC-MS. The only possible byproduct adipic acid was detected by a Shimadzu HPLC 2010AT by comparing with the standard of adipic acid. ${ }^{17}$ The errors in the yield measurements were estimated to be $3 \%$ except for the case of the ionic liquid [Omim] $\mathrm{Cl}$ (entry 3 in Table 1).

1 (a) R. Raja, G. Sankar and J. M. Thomas, J. Am. Chem. Soc., 1999, 121, 11926; (b) L. Liu, Y. Li, H. B. Wei, M. Dong, J. G. Wang, A. M. Z. Slawin, J. P. Li, J. X. Dong and R. E. Morris, Angew. Chem., Int. Ed., 2009, 48, 2206; (c) R. Kumar, S. Sithambaram and S. L. Suib, J. Catal., 2009, 262, 304.

2 (a) S. G. Shore, E. D. C. Park and M. A. Kean, J. Mol. Catal. A: Chem., 2004, 212, 291; (b) H. Z. Liu, T. Jiang, B. X. Han, S. G. Liang and Y. X. Zhou, Science, 2009, 326, 1250.

3 (a) M. Jhansi, L. Kishore, K. A. Anand and A. Kumar, Catal. Commun., 2008, 10, 285; (b) Y. H. Chang, T. Jiang, B. X. Han, L. A. Gao, R. Zhang, Z. M. Liu and W. Z. Wu, Ind. Eng. Chem. Res., 2003, 42, 6384.

4 X. Yuan, Q. H. Xia, H. J. Zhan, X. H. Lu and K. X. Su, Appl. Catal., A, 2006, 304, 178.

5 V. Rode, U. D. Joshi, O. Sato and M. Shirai, Chem. Commun., 2003, 1960.

6 D. Santhanaraj, C. Suresh, P. Vijayan, N. Venkatathri and K. Shanthi, React. Kinet. Mech. Catal., 2010, 99, 439.

7 (a) O. R. Hernandez, Green Chem., 2004, 6, 395; (b) R. Clift, Chem. Eng. Sci., 2006, 61, 4179.

8 (a) T. Welton, Chem. Rev., 1999, 99, 2071; (b) J. F. Brennecke and E. J. Maginn, AIChE J., 2001, 47, 2384; (c) H. O. Bourbigou, L. Magna and D. Morvan, Appl. Catal., A, 2010, 373, 1.

9 (a) S. Baj, A. Chrobok and R. Slupska, Green Chem., 2009, 11, 279; (b) C. A. Doorslaer, Y. Schellekens, P. Mertens, K. Binnemans and D. D. Vos, Phys. Chem. Chem. Phys., 2010, 12, 1741; (c) M. Herbert, E. Alvarez, D. J. C. Hamilton, F. Montilla and A. Galindo, Chem. Commun., 2010, 46, 5933.

10 Y. Usui and K. Sato, Green Chem., 2003, 5, 373.

11 (a) S. G. Zhang, X. J. Qi, X. Y. Ma, L. J. Lu and Y. Q. Deng, J. Phys. Chem. B, 2010, 114, 3912; (b) H. Tokuda, K. Hayamizu, K. Ishii, A. B. H. Susan and M. Watanabe, J. Phys. Chem. B, 2005, 109, 6103.

12 (a) C. Hardacre, J. D. Holbrey, S. P. Katdare and K. R. Seddon, Green Chem., 2002, 4, 143; (b) P. N. Davey, M. J. Davey, M. J. Earle, J. T. Hamill, S. P. Katdare, D. W. Rooney and K. R. Seddon, Green Chem., 2010, 12, 628.

13 (a) J. A. Boon, J. A. Levinsky, J. I. Pflug and J. S. Wilkes, J. Org.Chem., 1986, 51, 480; (b) A. C. Cole, J. L. Jensen, L. Ntai, K. L. T. Tran, K. J. Weaver, D. C. Forbes and J. H. Davis, J. Am. Chem. Soc., 2002, 124, 5962.

14 (a) Y. Zimmermann and S. Spange, J. Phys. Chem. B, 2002, 106, 12524; (b) N. M. Bertero, A. F. Trasarti, C. R. Apesteguia and A. J. Marchi, Appl. Catal., A, 2011, 394, 228.

15 S. G. Quero, F. C. Lizana and M. A. Keane, AIChE J., 2010, 56, 756.

16 (a) A. Klamt and F. Eckert, Fluid Phase Equilib., 2000, 172, 43; (b) F. Eckert and A. Klamt, AIChE J., 2002, 48, 369.

17 H. P. Nguyen, H. Matondo and M. Baboulene, Green Chem., 2003, 5, 303 . 